\title{
Stunted Too Early: Analysis of the Cambodia and Kenya 2014 Demographic and Health Survey
}

\section{Data}

Grace A. K. Ettyang ${ }^{1}$

Caroline J. Sawe ${ }^{1}$

Laban P. Ayiro ${ }^{2}$

1. Department of Human Nutrition, Moi University.

2. Daystar University

Corresponding author: Grace Ettyang, Department of Human Nutrition, Moi University; gaettyang@gmail.com or gaettyang@mu.ac.ke

\section{Acknowledgments}

This study was carried out with support provided by the United States Agency for International Development (USAID) through The DHS Program (\#AIDOAA-C-13-00095). The views expressed are those of the authors and do not necessarily reflect the views of USAID or the United States Government. The DHS Program assists countries worldwide in the collection and use of data to monitor and evaluate population, health, and nutrition programs. For additional information about the DHS Program contact:

DHS Program, ICF International, 530 Gaither Road, Suite 500, Rockville, MD 20850, USA. Phone: +1 301-407-6500; fax: +1 301-407-6501;

E-mail: reports@dhsprogram.com;

Internet: www.dhsprogram.com. 


\section{Abstract}

Background Child stunting reflects chronic under-nutrition, which often begins before birth and is almost irreversible after the second year of life. Globally, by 2018, an estimated 140 million children under the age of 5 years were stunted. Over one-third each lived in South East Asia (34.4\%) and Eastern and South Africa (33.6\%). This condition puts children at disadvantages due to partly irreversible physical and cognitive damage. This poorly nourished beginning has consequences that include persistent poverty, worsening inequality, higher health care costs and weaker national economies. Early detection of stunting is a key factor to any prevention strategy.

Objective To examine the relationship between child, maternal, household, and gender inequality characteristics with early onset of child stunting in Kenya and Cambodia.

Methods The study analyzed data from the 2014 Demographic and Health Surveys (DHS) in Kenya and Cambodia for children under age 2. Bivariate and logistic regression analyses were performed to find associations between the variables and child stunting.

Results The prevalence of stunting among children under age 2 in Kenya was 22\%, and in Cambodia, 25\%. Child's age, perceived birth size, family wealth status, and region of residence were significantly associated with stunting. In both countries children from the richest households had 0.4 times lower odds of being stunted compared with those from the poorest households. In Kenya, female children had 0.6 times lower odds of being stunted compared with male children. In Cambodia, children from rural areas had 0.6 times lower odds of being stunted compared with those from urban areas, while children whose mothers were underweight had 1.7 times higher odds of being stunted than children whose mothers were not underweight. In both countries, there was general lack of a strong and significant relationship between the DHS indicators of gender inequality and child stunting.

Conclusions Children's characteristics, household wealth and maternal underweight were more important in predicting stunting in these children under two years of age than factors related to gender inequality. A more extensive analysis of future DHS data that includes other aspects of gender inequality such as decisions on choice and preparation of food, purchase of household goods, as well as gender-based barriers to provision of child care might provide additional insights on that potential determinant of early stunting.

Keywords Stunting, Kenya, Cambodia, Gender Inequality and 1,000 Days. 


\section{Introduction}

In 2018 a global estimate of 140 million children under the age of 5 years were stunted (UNICEF DATA 2019). About one-third lived in South East Asia (34.4\%) and another one-third in Eastern and Southern Africa (33.6\%). This puts a total of about 87.7 million children in these two regions at risk of being stunted for life. Stunting is defined as having a height-for-age Z-score (HAZ) that is more than two standard deviations below the age-sex median for a well-nourished reference population (WHO 2006). Stunting has remained widespread in low- and middle-income countries (Hoddinott et al. 2013,), with the majority of stunted children living in Asia and sub-Saharan Africa (de Onis et al. 2012, UNICEF DATA 2019). The factors underlying this high prevalence of malnutrition include low birth weight, maternal health problems, poor child care related to dynamics within the family, and inequality between men and women (Ramalingaswami, Jonsson, and Rohde 1997)

The high prevalence of stunting in Africa and Asia is a public health problem that revolves around chronic hunger and poverty. The key factors include intrauterine growth retardation, poor feeding practices, and frequent exposure to infections (Long and Mulatu 2013). When stunting spans generations, it is linked to grave individual consequences that include a poor quality of life, morbidity, and mortality (Shroff et al. 2009; Black et al. 2013;). At national level this poorly nourished beginning has consequences that include persistent poverty, worsening inequality, higher health care costs and weaker national economies.

The 2014 Demographic and Health Surveys (DHS surveys) for Kenya and Cambodia showed that the prevalence of stunting among children under age 2 was $22 \%$ and $25 \%$ respectively. The prevalence of stunting in children under age 5 in Kenya and Cambodia was higher, at $32 \%$ and 26\% respectively (National Institute of Statistics et al 2015; KDHS 2014). The first 1,000 days between a woman's pregnancy and a child's second birth day is widely recognized as the key 'window of opportunity' for reducing stunting (Victora et al. 2010). A focus on stunting prevalence, in the under-five age group as a whole, masks the early onset of stunting among children. The potential for reducing child stunting is only under age 2 . The benefit is greatest if nutrition and health interventions focus on the first 1,000 days (Ruel and Alderman 2013). So far, however, the nutrition interventions made during this crucial time have had only a modest impact on child stunting (Bhutta et al. 2013).

The conditions of care and feeding practices shape the family capacity and ability to prevent the irreversible impact of child stunting. A number of studies have identified risk factors for stunting in this crucial period (Semba et al. 2016). Researchers have found that poverty, poor health and nutrition and social factors are associated with risks to child growth. These factors have prevented over 200 million children in developing countries from attaining their full potential (Walker et al. 2007, UNICEF DATA 2019). In general, it is expected that gender inequality is likely to be associated with maternal nutritional status and breastfeeding patterns. These are key factors in efforts to reduce stunting before the age of 2 years. A 2006 UNICEF reportedly found a link between children's nutritional status and women's decision-making power. In developing countries, where women are often denied an equal voice in household decisions, they are most likely to be undernourished themselves and less likely to have access to resources that can be directed toward children's nutrition (UNICEF 2006). Therefore, women should be given a chance 
to participate in household decisions, which might also have a positive impact on the nutritional status of their children (Ramalingaswami, Jonsson, and Rohde 1997). Global attention to child stunting has recently brought a lot of support for nutrition. To maintain this momentum requires a focus on what will truly make a difference in lives of children. This may require a fresh application of a gender inequality lens to factors associated with child stunting.

International goals to reduce stunting (Alkire and Samman 2014; de Onis et al. 2013 ) cannot be achieved if factors specific to stunting in children under age 2 are ignored. The World Health Assembly aims to reduce the level of child stunting in the world by 40\% by 2025 (World Health Organization 2012). Because sub-Saharan Africa has the highest share of child stunting in the world, followed by South Asia, there is a need to investigate the factors associated with the high prevalence of child stunting in these regions.

Reduction in child stunting is a key indicator for achievement of Sustainable Development Goal Number 2 (Murray 2015) and is considered a good indicator of chronic malnutrition that is associated with inadequate nutrition and infectious disease (Richard et al. 2012). If malnutrition is addressed before the age of 2 years, accelerated growth can occur and the original height trajectory achieved (Van IJzendoorn, Bakermans-Kranenburg, and Juffer 2007).

This study therefore investigated the maternal, household, and gender factors that are associated with stunting among children under age 2 in Kenya and Cambodia, using data from the 2014 Demographic and Health Survey (DHS) in each country.

\section{Conceptual Framework}

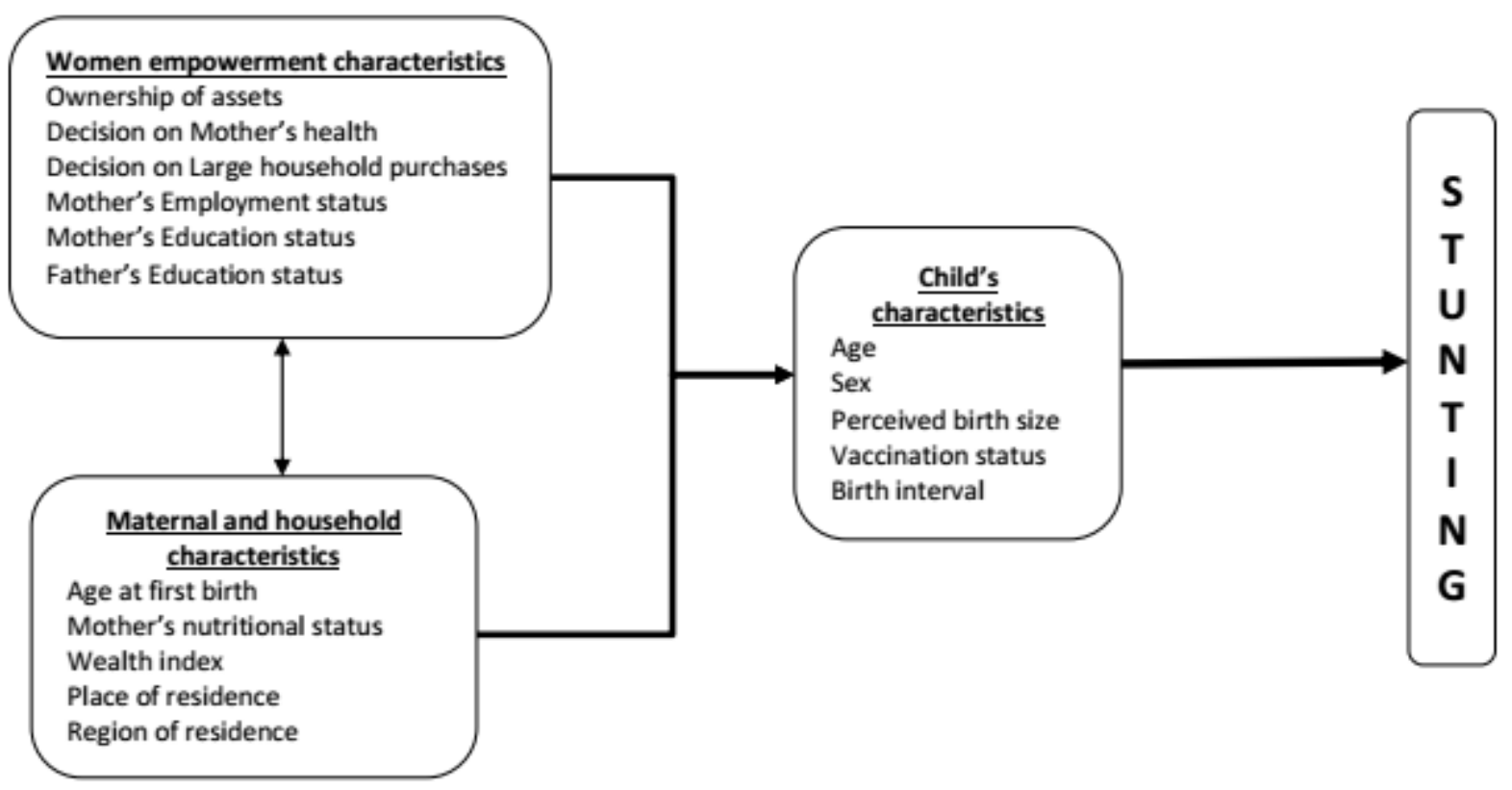




\section{Research questions}

1. Are factors associated with stunting in children under age 2 different for Kenya compared with Cambodia?

2. To what extent are gender inequalities in Kenya and Cambodia a significant factor for stunting in children under age 2 ?

\section{Data and methods}

The study used data from the 2014 Kenya and Cambodia DHS surveys. The 2014 Kenya DHS contained both a long and short questionnaire. For this analysis, the data for Kenya were all from the long questionnaire, which included many of the variables used in this analysis (namely the gender inequality variables, father's education level, perceived birth size, and mother's nutritional status). DHS data are cross-sectional in nature, and data about children are obtained from their mothers.

Our study specifically examined stunting among children under age 2 and its association with child, maternal, household, and gender factors. The sample size was limited to children under age 2 with valid anthropometric measurements and whose parents were married and or declared that they were in a union. Information that is collected only from women in union in the surveys are required to construct gender variables. Figure 2 shows the procedure for sample size determination.

In addition, when constructing the mother's nutritional status variable, pregnant women and women with a child under age 2 months were coded as missing. This created 325 missing cases for this variable in Kenya and 202 in Cambodia.

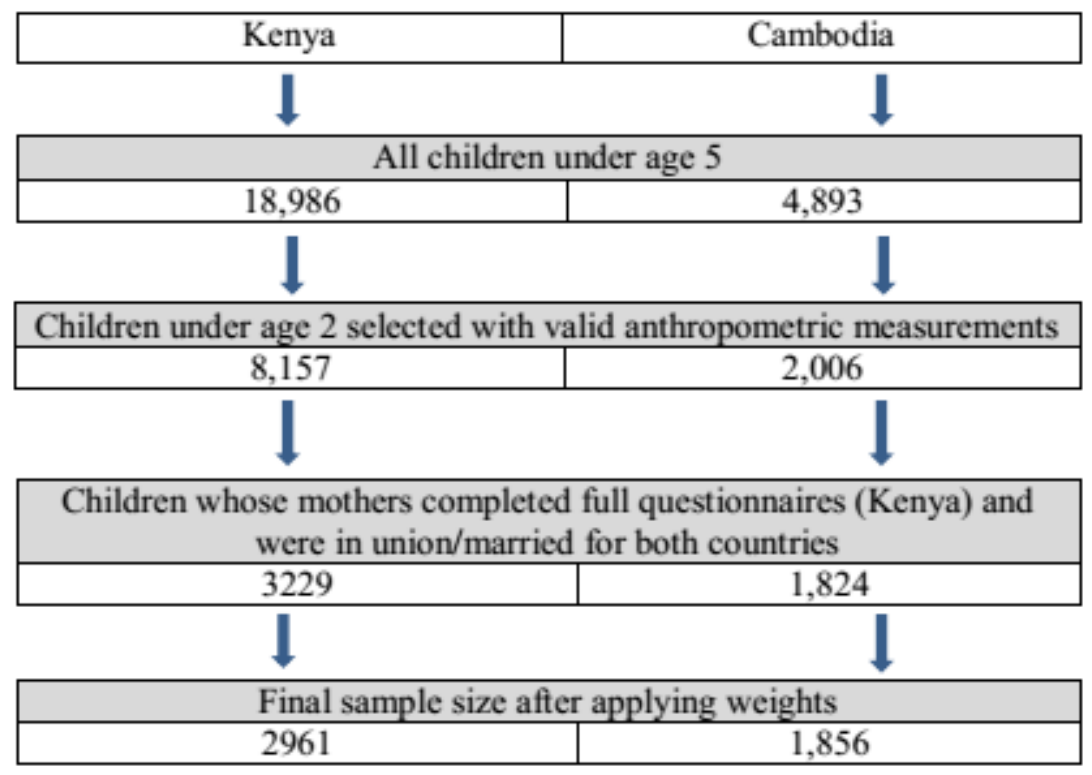

Figure 2. Analysis of sample derivation 


\section{Dependent variable}

Stunting: The 2014 Kenya and Cambodia DHS measured stunting by height-for-age according to WHO recommendations (WHO 2006). To increase data quality and minimize errors, the field staff were thoroughly trained and a pilot study was done prior to the main survey. Height-for-age, Zscores were tabulated. A Z-score less than -2 standard deviations (SD) for height-for-age indicated stunting based on the WHO/National Center for Health Statistics reference (WHO 2006). A binary variable was created to define stunting, "not stunted" (Z-score greater than -2 SD) and "stunted" (Z- score less than and equal to -2 SD).

\section{Independent variables}

\section{Child characteristics}

The child variables included children's age in months (0-24 months), sex, perceived birth size by the mother (small, average and large; there were a large number of missing responses from mothers who were asked the exact weight of their child at birth), and the birth interval between the current child of interest and the previous birth, counting twins as one child? and giving an interval of zero for first births. Vaccination status was coded as yes or no to indicate whether the child had received all the necessary DPT, measles, polio, and BCG vaccinations at the time of the survey.

\section{Maternal and household characteristics}

The maternal variables included mother's age at first birth, mother's nutritional status, which was based on Body Mass Index (BMI), defined as weight in kilograms divided by height in meters $\left(\mathrm{W} / \mathrm{H}^{2}\right)$. Women who were pregnant and women with a child under age 2 months were excluded from the BMI calculation. The BMI was then used to identify mothers as either underweight (BMI less than 18.5) or not. The household variables included wealth index, place of residence (urbanrural), and region.

\section{Gender inequality characteristics}

Decisions on the mother's healthcare: In the survey, women were asked if they make decisions about their own health alone or jointly with their husbands or partners. Women's responses that they made decisions alone or jointly with their husbands or partners were categorized as yes, while responses that the husbands, partners, or others made the decisions were categorized as no.

Ownership of assets: Women were asked if they owned any land or a house. If they owned property alone or jointly with their husbands or partners, we categorized this as yes, but if their husbands or partners owned such assets alone, we categorized it as no.

Mother's work status: Women were asked if they ever worked for pay in the last 12 months. Those who reported not working were categorized as no, and those worked in the past 12 months or were currently working or on leave from work were categorized as yes. 
Education level: This category, for both women and men, was defined as the highest education level attended: no education, primary, secondary, and higher. The categories of secondary and higher were combined to create a category of secondary and above.

\section{Statistical analysis}

Statistical analyses were carried out using STATA 14. The datasets for households and women were used and the "sample weight" variable was used to adjust for disproportionate sampling and non-response. Two-stage sampling design was used, where clusters were selected first and then the households to be interviewed were chosen. Univariate analysis was performed to describe all the variables (Table 1). Bivariate analysis with Chi-square statistics was performed to test the independence of distribution between the independent variables and the dependent variable (Table 2 ), and a final logistic regression was done to assess the net associations of all variables with stunting. Three models were generated: (1) a model with child characteristics only; (2) a model with child, maternal, and household characteristics; and (3) a model with the all of the characteristics, including gender inequality variables (Table 3). The associations between the outcome and main explanatory variables were considered to be statistically significant when the p-value $<0.05$.

\section{Results}

The final sample size for Kenya was 2,961 women and for Cambodia 1,856 women who were interviewed in the 2014 DHS, had children under age 2, and were in a union at the time of the survey. Table 1 presents the descriptive statistics of the child, maternal, household, and gender inequality variables. The prevalence of stunting among children under age 2 was $22 \%$ in Kenya and 25\% in Cambodia. In Kenya, 50\% of the children were male, with a majority age 18-24 months (28\%), compared with 52\% males in Cambodia, with 29\% age 18-24 months. According to their mothers' perceptions, $16 \%$ of children in Kenya and 10.8\% in Cambodia were born with a small birth size.

An estimated $62 \%$ of Kenyan mothers and $69 \%$ of Cambodian mothers reported giving birth to their first child at age 18-24. The great majority of mothers were not underweight (Kenya 90\% and Cambodia 86\%). In addition, $64 \%$ of Kenyan children and $86 \%$ of Cambodian children lived in rural areas.

In both countries most women stated that they had a say in decisions on their own healthcare, at 76\% in Kenya and 91\% in Cambodia. In Cambodia, 92\% of women were involved in the purchase of large household items compared with 66\% in Kenya. Concerning ownership of property, in Kenya $60 \%$ of women reported owning a house and 53\% owned land, while in Cambodia 63\% owned a house and 55\% owned land. Both countries had similar percentages for women who were working, at $64 \%$, and the level of education attained was also similar, with primary highest at 54\%. Forty percent of the fathers in Kenya and $46 \%$ in Cambodia had secondary and above as the highest level of education.

Table 2 shows the results of bivariate analysis on the association between background characteristics of the sample and child stunting. In both Kenya and Cambodia, the factors 
negatively associated with stunting were child's age, perceived birth size, positive vaccination status, place of residence, father's highest attained education, and wealth index. The following factors were negatively associated with stunting in Kenya alone: child's birth interval, sex of the child (female), mother's age, and mother's highest attained education. In Cambodia alone negative associations included region and, surprisingly, mother's ownership of a house.

Table 3 summarizes the results of the three logistic regression models to assess the net association of all variables with stunting. As mentioned, the first model included child characteristics only, the second included child, maternal, and household characteristics, and the third contained all of the characteristics, including gender inequality variables. Before running the regression, the correlations between the independent variables used in the analysis were checked, and none of them were highly inter-correlated.

In the first model, the child characteristics that were significantly associated with stunting for both countries were age, sex, and perceived birth size, and for Kenya alone birth interval. In Kenya, children aged 18-24 months had 5.6 times higher odds of being stunted compared with children under age 6 months [OR= 5.6; CI 3.6,8.7], and in Cambodia, 3.8 times higher odds [OR 3.8; CI 2.3,6.2]. Children with average perceived birth size had 0.5- and 0.4-times lower odds, for Kenya and Cambodia respectively, of being stunted compared with children whose mothers perceived them to be small at birth [OR = 0.5; CI 0.3, 0.6 for Kenya, and OR = 0.4; CI 0.3, 0.6 for Cambodia]. Female children had lower odds of being stunted compared with male children [OR = 0.6; CI 0.5, 0.8 for Kenya and OR =0.8; CI 0.6, 1.0 for Cambodia]. In Kenya, children whose birth was followed by a subsequent birth more than 47 months later had 0.6 times lower odds of being stunted compared with children with a subsequent birth interval of less than 24 months.

In the second model, the variables for child, maternal, and household characteristics that were significantly associated with stunting in both countries included child's age, perceived birth size, wealth index, and region of residence. For the child characteristics that remained significant in the second model, the odds ratios did not change substantially from the first model. In the second model child's sex was no longer significant in Cambodia, and child's birth interval was not significant in either country. In Kenya alone, child's sex was significant for predicting stunting, and in Cambodia alone the significant variables were mother's nutritional status and child's place of residence. In both countries, children in the richest households had 0.4 times lower odds of being stunted compared with children in the poorest households [Kenya OR 0.4; CI 0.2-0.7 and Cambodia OR 0.4; CI 0.2-0.8]. In Cambodia alone, children in rural areas had 0.6 times lower odds of being stunted compared with children in urban areas [OR 0.6; CI 0.4-0.9], while children whose mothers were underweight had 1.7 times higher odds of being stunted compared with children whose mothers were not underweight [OR 1.7; CI 1.1-2.7]

In the third model, which included all child, maternal, household, and gender characteristics, none of the gender inequality variables were significantly associated with child stunting, for either country. Child's age, perceived birth size, household wealth status, and region of residence showed some association with stunting in both countries, while child's sex was significant in Kenya alone, and mother's nutritional status and child's place of residence were significant in Cambodia alone. 


\section{Discussion}

The first 1,000 days of an infant's life, from conception until age 2, are a crucial period in which inadequate nutrition and bouts of infection can result in stunting that is then largely irreversible (Save the Children 2012) . In adults, the effect of childhood stunting has been linked to diminished cognitive and physical development, reduced productive capacity, and poor health.

In Kenya and Cambodia, the prevalence of stunting among children under age 2 was 22\% and 25\% respectively, and stunting became even more prevalent among children age 18-24 months, at 33\% in Kenya and 34\% in Cambodia. This rising risk of stunting with age suggests that for young children the window of opportunity for reversing the negative effects of stunting might be lost forever. After 6 months of exclusive breastfeeding, children should be introduced to complementary feeds even as they continue being fed with breast milk. In poor settings, however, the quality of these complimentary feeds may be compromised. Because young children have increased nutritional needs due to their rapid growth, inadequate nutrition might negatively affect their chances for optimal growth. It is therefore important that expectant mothers get vital nutrients, babies be breastfed exclusively for six months, and adequate nutritious solid foods be introduced at the right time. Throughout childhood, adequate healthcare and good hygiene and sanitation are vital.

In both Kenya and Cambodia, child's age, perceived birth size, wealth index, and region of residence were significantly associated with stunting. In Cambodia alone, mother's nutritional status was also significantly associated with stunting. This finding was in tandem with a study in Cambodia in 2013 that found age, wealth, and maternal nutritional status to be associated with child stunting (Ikeda, Irie, and Shibuya 2013).

Our study agrees with a study by Miller and Rodgers that found no association between either child vaccination or perceived birth size with child stunting (Miller and Rodgers 2009), but it contradicts a study in Nigeria that found child vaccination was associated with child stunting (Adekanmbi, Kayode, and Uthman 2013). With vaccination, there is usually a buildup of the immune system, which has a positive effect on the nutritional status of children. This study also contradicts a study by Black and colleagues that had showed that $20 \%$ of stunted children in lowand middle-income countries had small size at birth (Black et al. 2013). In our study this is reported as $16.2 \%$ for Kenya and $10.8 \%$ for Cambodia.

Our study found higher risk for stunting among males compared with females in Kenya but not in Cambodia. Studies have shown that males are more likely to become stunted in their first year of life, and females are likely to become stunted in their second year (Adair and Guilkey 1997). In almost all countries with available data, stunting rates are higher among boys than girls. Higher risk for preterm birth among boys (Peelen MJ et al. 2016) is a potential reason for this sex-based disparity in stunting. Male children may have early exposure to early inappropriate weaning practices and complimentary feedings especially in low- and middle-income countries and in African culture. For example, they may be introduced to high status or expensive supplements earlier and thus receive less exclusive breastfeeding.

Manifestation of stunting is in children below the age of five years is generally an indicator of chronic under-nutrition. Studies have shown that stunting is more common among children who 
live in poor households (Ikeda, Irie, and Shibuya 2013). Our study also found that children from the poorest families were more likely to be stunted early. This could be because they lack the resources for obtaining healthcare services and for adequate nutrition. The rich-poor gap is increasing in a majority of low-income countries.

Gender, as it relates to women's empowerment, may be a key factor responsible influencing children's nutritional status (Shroff et al. 2009). Ownership of assets by women has increasingly been put forth as a means of empowering women, increasing their productivity, and improving their welfare. A study by Bhutta and colleagues (2013) found that women who owned land were significantly more likely to have the final say in household decisions, which is a measure of empowerment. Similarly, children of mothers who own land were significantly less likely to be severely underweight (Bhutta et al. 2013). A study in Indonesia and Bangladesh concluded that both maternal and paternal education were strong determinants of child stunting (Semba et al. 2008).

These findings do not agree with our findings of no association between gender characteristics and child stunting in Kenya and Cambodia. This difference may be related to the way data are structured and collected and the relatively longer pathway from gender inequality to stunting in comparison with more direct factors, such as children's characteristics, maternal nutritional status and breastfeeding patterns. For example, we combined women's decision making and ownership with partial decision making and ownership. Current survey data on women's empowerment are limited in scope and focus only on married couples. Most data are collected from only one household member, and thus the DHS may not capture intra-household gender inequalities.

\section{Conclusions}

Nutrition is key to children's survival, growth, and development. Well-nourished children are healthier than undernourished children, they can grow and develop to their full potential, and they perform better in school and as adults. Despite many interventions for improving child stunting, about a quarter of children under age 2 in Kenya (22\%) and Cambodia (25\%) are stunted. In both countries stunting appears to be strongly associated with child's age, perceived birth size, household wealth index, and region of residence. In our study, factors related to women's empowerment were not associated with stunting. For future analysis, use of a more extensive DHS gender inequality data set may establish a more significant association of gender inequalities and child stunting.

\section{Policy recommendations}

Since stunting is a key measure obtained in DHS surveys, we suggest that its usefulness as a measure of achievement of the UN Sustainable Development Goals would be enhanced if future survey instruments could incorporate an easy linkage of stunting to more comprehensive data on gender. Just as The DHS Program has the Service Provision Assessment (SPA) and Geographic Information Systems (GIS) tools, there may be a need for developing an Assessment of Gender Inequality tool (AGI). The Women's Empowerment in Agricultural Index (WEAI) has such an instrument (Alkire et al. 2013). There is also a need for governments to introduce nutrition 
interventions that target children under age 2 in order to combat stunting and malnutrition among this key group. This would be of great importance in achieving the Sustainable Development goals.

\section{References}

Adair, L.S., and D.K. Guilkey. 1997. "Age-specific determinants of stunting in Filipino children." The Journal of Nutrition 127 (2):314-320.

Adekanmbi, V.T., G.A. Kayode, and O.A. Uthman. 2013. "Individual and contextual factors associated with childhood stunting in Nigeria: A multilevel analysis." Maternal \& Child Nutrition 9 (2):244-259.

Alkire, S., and E. Samman. 2014. Mobilising the Household Data Required to Progress Toward the SDGs. OPHI Working Paper.

Alkire, S., et al. 2013. “The Women's Empowerment in Agriculture Index.” World Development 52:71-91.

Bhutta, Z., J. Das, N. Walker, A. Rizvi, H. Campbell, I. Rudan, R. Black, T.L. Diarrhoea, and P.I.S. Group. 2013. "Interventions to address deaths from childhood pneumonia and diarrhea equitably: What works and at what cost?" Lancet 381:1417 - 1429.

Black, R.E., C.G. Victora, S.P. Walker, Z.A. Bhutta, P. Christian, M. De Onis, M. Ezzati, S. Grantham-McGregor, J. Katz, and R. Martorell. 2013. "Maternal and child undernutrition and overweight in low-income and middle-income countries." The Lancet 382 (9890):427-451.

CDHS. 2014. "Cambodia Demographic and Health Survey." In, ed. National Institute of Statistics Ministry of Planning, Cambodia Phnom Penh, Directorate General for Health Ministry of Health, Cambodia Phnom Penh, Royal Government of Cambodia (RGC), United States Agency for International Development (USAID), Australian Department of Foreign Affairs and Trade (AustraliaDFAT), United Nations Population Fund (UNFPA), United Nations Children's Fund (UNICEF), Japan International Cooperation Agency (JICA), Korean International Cooperation Agency (KOICA), ICF Macro MEASURE DHS, Maryland, Calverton, U.S.A.,. https://dhsprogram.com/pubs/pdf/FR312/FR312.pdf. de Onis, M., M. Blössner, and E. Borghi. 2012. "Prevalence and trends of stunting among preschool children, 1990-2020." Public Health Nutrition 15 (01):142-148.

de Onis, M., D. Brown, M. Blössner, and E. Borghi. 2012. "Levels and trends in child malnutrition." UNICEF-WHO-The World Bank Joint Child Malnutrition Estimates:9-10.

de Onis, M., K.G. Dewey, E. Borghi, A.W. Onyango, M. Blössner, B. Daelmans, E. Piwoz, and F. Branca. 2013. "The World Health Organization's global target for reducing childhood stunting by 2025: Rationale and proposed actions." Maternal \& Child Nutrition 9:6-26.

Dewey, K.G., and K. Begum. 2011. "Long-term consequences of stunting in early life." Maternal \&Child Nutrition 7 (s3):5-18.

Hoddinott, J., H. Alderman, J.R. Behrman, L. Haddad, and S. Horton. 2013. "The economic rationale for investing in stunting reduction." Maternal \& Child Nutrition 9:69-82.

Ikeda, N., Y. Irie, and K. Shibuya. 2013. "Determinants of reduced child stunting in Cambodia: Analysis of pooled data from three Demographic and Health Surveys." Bulletin of the World Health Organization 91 (5):341-349. 
KDHS. 2014. "Kenya Demographic and Health Survey." In, ed Kenya National Bureau of Statistics, Kenya Nairobi, National AIDS Control Council, Kenya Nairobi, National AIDS/STD Control Programme, Kenya Nairobi, Ministry of Public Health and Sanitation, Kenya Nairobi, Kenya Medical Research Institute, Kenya Nairobi, National Coordinating Agency for Population and Development, Kenya Nairobi, ICF Macro MEASURE DHS, Maryland Calverton, U.S.A.,, U.S. Agency for International Development (USAID), Kenya Nairobi and United Nations Population. http://www.dhsprogram.com/publications/publication-fr308-dhs-final-reports.cfm.

Long, L.A., and T. Mulatu. 2013. "Getting community-level training right: Important lessons from Ethiopia." Africa Health 35 (3):22-23.

Miller, J.E., and Y.V. Rodgers. 2009. "Mother's education and children's nutritional status: New evidence from Cambodia." Asian Development Review 26 (1):131.

Murray, C.J. 2015. "Shifting to sustainable development goals_-Implications for global health." New England Journal of Medicine 373 (15):1390-1393.

Peelen, M.J., Kazeimer, B.M., Ravelli, A.C., De Groot C.J., van Der Post, J,A., Mel, B.W., Hajenius, P.J., Kok, M. (2016) "Impct of fetal gender on the risk of preterm birth, a national cohort study.” Acta Obstel Gynecol Scand 95(9):1034-41.

Doi:10.1111/aogs.12929

Ramalingaswami, V., U. Jonsson, and J. Rohde. 1997. Malnutrition: A south asian enigma. In Popline.

Richard, S.A., R.E. Black, R.H. Gilman, R.L. Guerrant, G. Kang, C.F. Lanata, K. Mølbak, Z.A. Rasmussen, R.B. Sack, and P. Valentiner-Branth. 2012. "Wasting is associated with stunting in early childhood." The Journal of Nutrition 142 (7):1291-1296.

Ruel, M.T., and H. Alderman. 2013. "Nutrition-sensitive interventions and programmes: How can they help to accelerate progress in improving maternal and child nutrition?" The Lancet 382 (9891):536-551.

Save the Children. 2012. Nutrition in the first 1,000 days. State of the world's mothers 2012. Save the Children Westport, CT.

Semba, R.D, S. de Pee, K. Sun, M. Sari, N. Akhter, and M.W. Bloem. 2008. "Effect of parental formal education on risk of child stunting in Indonesia and Bangladesh: A cross-sectional study." The Lancet 371 (9609):322-328.

Semba, R.D., M. Shardell, F.A.S. Ashour, R. Moaddel, I. Trehan, K.M. Maleta, M.I. Ordiz, K. Kraemer, M.A. Khadeer, and L. Ferrucci. 2016. "Child stunting is associated with low circulating essential amino acids." EBioMedicine 6:246-252.

Shroff, M., P. Griffiths, L. Adair, C. Suchindran, and M. Bentley. 2009. "Maternal autonomy is inversely related to child stunting in Andhra Pradesh, India." Maternal \& Child Nutrition 5 (1):64-74.

UNICEF. 2006. Women and Children: The Double Dividend of Gender Equality. The State of the World's Children 2007. UNICEF.

UNICEF DATA. (April) 2019. Malnutrition in Children. https://data.unicef.org.

Van IJzendoorn, M.H., M.J. Bakermans-Kranenburg, and F. Juffer. 2007. "Plasticity of growth in height, weight, and head circumference: Meta-analytic evidence of massive catch-up after international adoption." Journal of Developmental \& Behavioral Pediatrics 28 (4):334-343. 
Victora, C.G., M. de Onis, P.C. Hallal, M. Blössner, and R. Shrimpton. 2010. "Worldwide timing of growth faltering: Revisiting implications for interventions." Pediatrics 125 (3):e473-e480.

Walker, S.P., T.D. Wachs, J.M. Gardner, B. Lozoff, G.A. Wasserman, E. Pollitt, J.A. Carter, and I.C.D.S. Group. 2007. "Child development: Risk factors for adverse outcomes in developing countries." The Lancet 369 (9556):145-157.

World Health Organization. 2012. Proposed Global Targets for Maternal, Infant, and Young Child Nutrition: Summary of Main Issues Raised and WHO Responses (4 April). Geneva: World Health Organization. 
Table 1. Descriptive characteristics of the sample in Kenya and Cambodia, 2014 DHS

\begin{tabular}{|c|c|c|c|c|c|c|}
\hline & \multicolumn{3}{|c|}{ KENYA } & \multicolumn{3}{|c|}{ CAMBODIA } \\
\hline Variable & $\%$ & CI & $\mathbf{N}$ & $\%$ & CI & $\mathbf{N}$ \\
\hline \multicolumn{7}{|l|}{ Nutrition status } \\
\hline Not stunted & 77.9 & {$[75.8,80.0]$} & 2,308 & 75.5 & {$[73.0,77.9]$} & 1,402 \\
\hline Stunted & 22.1 & {$[20.0,24.2]$} & 653 & 24.5 & {$[22.1,27.0]$} & 454 \\
\hline \multicolumn{7}{|l|}{ Age of child } \\
\hline Under 6 months & 25.5 & {$[23.4,27.6]$} & 772 & 28.3 & {$[25.8,30.9]$} & 552 \\
\hline 6-8 months & 8.7 & {$[7.4,10.1]$} & 263 & 8.1 & {$[6.6,10.0]$} & 159 \\
\hline 9-11 months & 12.4 & {$[11.0,13.9]$} & 374 & 11.4 & {$[9.7,13.4]$} & 223 \\
\hline 12-17 months & 26.0 & {$[23.8,28.4]$} & 789 & 23.1 & {$[20.8,25.6]$} & 451 \\
\hline 18-24 months & 27.5 & {$[25.5,29.5]$} & 833 & 29.1 & {$[26.7,31.6]$} & 567 \\
\hline \multicolumn{7}{|l|}{ Child's birth size } \\
\hline Small & 16.2 & {$[14.5,18.0]$} & 485 & 10.8 & {$[9.0,12.9]$} & 209 \\
\hline Average & 57.4 & {$[54.9,59.8]$} & 1,722 & 54.8 & {$[51.7,57.8]$} & 1,062 \\
\hline Large & 26.5 & {$[24.4,28.6]$} & 794 & 34.4 & {$[31.5,37.4]$} & 667 \\
\hline \multicolumn{7}{|l|}{ Birth interval } \\
\hline$<24$ & 32.5 & {$[30.4,34.7]$} & 985 & 8.4 & {$[6.9,10.1]$} & 164 \\
\hline $24-47$ & 40.0 & {$[37.7,42.5]$} & 1,214 & 24.4 & {$[22.0,27.0]$} & 477 \\
\hline $47+$ & 27.5 & {$[25.4,29.7]$} & 833 & 67.2 & {$[64.3,69.9]$} & 1,311 \\
\hline \multicolumn{7}{|c|}{$\begin{array}{l}\text { Received all required vaccinations (DPT, Polio, } \\
\text { BCG, and Measles) }\end{array}$} \\
\hline Yes & 58.4 & {$[56.1,60.8]$} & 1,771 & 56.4 & {$[53.4,59.4]$} & 1,101 \\
\hline No & 41.6 & {$[39.2,43.9]$} & 1,260 & 43.6 & {$[40.6,46.6]$} & 851 \\
\hline \multicolumn{7}{|l|}{ Sex of child } \\
\hline Male & 50.5 & {$[48.1,52.9]$} & 1,531 & 52.4 & {$[49.2,55.5]$} & 1,022 \\
\hline Female & 49.5 & {$[47.1,51.9]$} & 1,500 & 47.6 & {$[44.5,50.8]$} & 930 \\
\hline \multicolumn{7}{|c|}{ Mother's nutritional status } \\
\hline Not underweight & 90.9 & {$[89.5,92.1]$} & 2,459 & 85.9 & {$[83.6,87.9]$} & 1,503 \\
\hline
\end{tabular}


World Nutrition 2019(10):63-85

\begin{tabular}{|c|c|c|c|c|c|c|}
\hline Underweight & 9.1 & {$[7.9,10.5]$} & 246 & 14.1 & {$[12.1,16.4]$} & 247 \\
\hline Total & 100 & & 2,706 & 100 & & 1,750 \\
\hline \multicolumn{7}{|c|}{ Mothers age at 1st birth } \\
\hline$<18$ & 29.4 & {$[27.3,31.6]$} & 891 & 8.4 & {$[7.0,10.1]$} & 164 \\
\hline $18-24$ & 61.5 & {$[59.2,63.8]$} & 1,865 & 68.9 & {$[66.3,71.5]$} & 1,346 \\
\hline $25+$ & 9.1 & {$[7.8,10.6]$} & 275 & 22.6 & {$[20.2,25.2]$} & 442 \\
\hline \multicolumn{7}{|l|}{ Wealth index } \\
\hline Poorest & 25.5 & {$[23.1,28.1]$} & 773 & 24.7 & {$[21.3,28.3]$} & 481 \\
\hline Poorer & 19.8 & {$[18.0,21.8]$} & 601 & 19.6 & {$[17.3,22.2]$} & 383 \\
\hline Middle & 16.8 & {$[15.2,18.6]$} & 511 & 20.1 & {$[17.7,22.8]$} & 393 \\
\hline Richer & 17.1 & {$[15.1,19.3]$} & 517 & 17.6 & {$[15.2,20.3]$} & 344 \\
\hline Richest & 20.8 & {$[18.2,23.5]$} & 629 & 18 & {$[15.6,20.6]$} & 351 \\
\hline \multicolumn{7}{|l|}{ Region, Kenya } \\
\hline Coast & 10.3 & {$[8.7,12.2]$} & 313 & & & \\
\hline North Eastern & 3.8 & {$[3.1,4.8]$} & 116 & & & \\
\hline Eastern & 12.1 & {$[10.6,13.8]$} & 368 & & & \\
\hline Central & 9.2 & {$[7.8,10.9]$} & 279 & & & \\
\hline Rift Valley & 29.2 & {$[27.0,31.6]$} & 886 & & & \\
\hline Western & 11.9 & {$[10.0,14.1]$} & 360 & & & \\
\hline Nyanza & 13.3 & {$[11.8,14.9]$} & 403 & & & \\
\hline Nairobi & 10.1 & {$[8.3,12.3]$} & 307 & & & \\
\hline \multicolumn{7}{|l|}{$\underline{\text { Region, Cambodia }}$} \\
\hline Banteay mean chey & & & & 3.8 & {$[2.8,5.0]$} & 74 \\
\hline Kampong cham & & & & 12.8 & {$[10.6,15.5]$} & 250 \\
\hline Kampong chhnang & & & & 3.8 & {$[3.2,4.5]$} & 74 \\
\hline Kampong speu & & & & 6.8 & {$[5.1,8.9]$} & 132 \\
\hline Kampong thom & & & & 4.8 & {$[4.0,5.9]$} & 95 \\
\hline Kandal & & & & 6.8 & {$[5.4,8.5]$} & 132 \\
\hline Kratie & & & & 3.9 & {$[2.6,5.7]$} & 76 \\
\hline
\end{tabular}




\begin{tabular}{|c|c|c|c|c|c|c|}
\hline Phnom Penh & & & & 8.4 & {$[6.8,10.3]$} & 164 \\
\hline Prey Veng & & & & 6.9 & {$[5.6,8.3]$} & 134 \\
\hline Pursat & & & & 4.4 & {$[3.3,5.9]$} & 86 \\
\hline Siem Reap & & & & 6.8 & {$[5.4,8.5]$} & 133 \\
\hline Svay Rieng & & & & 3.8 & {$[3.1,4.7]$} & 75 \\
\hline Takeo & & & & 5.4 & {$[4.4,6.6]$} & 106 \\
\hline Otdar Mean Chey & & & & 2 & {$[1.6,2.4]$} & 38 \\
\hline Battambang \& Pailin & & & & 7.7 & {$[5.3,11.2]$} & 151 \\
\hline Kampot \& Kep & & & & 4.3 & {$[3.5,5.1]$} & 83 \\
\hline \multicolumn{2}{|c|}{ Preah Sihanouk \& Kaoh Kong } & & & 2.1 & {$[1.7,2.6]$} & 40 \\
\hline \multicolumn{2}{|c|}{ Preah Vihear \& Steung Treng } & & & 3 & {$[2.3,4.0]$} & 59 \\
\hline \multicolumn{2}{|c|}{ Mondol Kiri \& Rattanak Kiri } & & & 2.6 & {$[2.0,3.3]$} & 51 \\
\hline \multicolumn{7}{|l|}{ residence } \\
\hline Urban & 36 & {$[33.4,38.6]$} & 1,090 & 13.9 & {$[12.2,15.7]$} & 271 \\
\hline Rural & 64 & {$[61.4,66.6]$} & 1,941 & 86.1 & {$[84.3,87.8]$} & 1,680 \\
\hline \multicolumn{7}{|c|}{ Mother decides on own healthcare (alone or jointly) } \\
\hline No & 24.8 & {$[22.8,27.0]$} & 752 & 9.4 & {$[7.8,11.4]$} & 184 \\
\hline Yes & 75.2 & {$[73.0,77.2]$} & 2,276 & 90.6 & {$[88.6,92.2]$} & 1,767 \\
\hline \multicolumn{7}{|c|}{$\begin{array}{l}\text { Mother decides on household large purchases (alone or } \\
\text { jointly) }\end{array}$} \\
\hline No & 34.0 & {$[31.4,36.7]$} & 1,029 & 8.5 & {$[7.0,10.3]$} & 167 \\
\hline Yes & 66.0 & {$[63.3,68.6]$} & 1,998 & 91.5 & {$[89.7,93.0]$} & 1,784 \\
\hline \multicolumn{7}{|c|}{$\begin{array}{l}\text { Mother owns house (alone or } \\
\text { jointly) }\end{array}$} \\
\hline No & 39.9 & {$[37.0,42.7]$} & 1,206 & 37.3 & {$[34.4,40.3]$} & 728 \\
\hline Yes & 60.1 & {$[57.3,63.0]$} & 1,820 & 62.7 & {$[59.7,65.6]$} & 1,224 \\
\hline \multicolumn{7}{|c|}{$\begin{array}{l}\text { Mother owns land (alone or } \\
\text { jointly) }\end{array}$} \\
\hline No & 46.6 & {$[44.0,49.3]$} & 1,411 & 45.4 & {$[42.2,48.6]$} & 886 \\
\hline Yes & 53.4 & {$[50.7,56.0]$} & 1,616 & 54.6 & {$[51.4,57.8]$} & 1,066 \\
\hline
\end{tabular}


World Nutrition 2019(10):63-85

\begin{tabular}{|l|l|l|l|l|l|l|}
\hline \multicolumn{2}{|l|}{ Mother worked in the past 12 months } & & & & \\
\hline No & 36.5 & {$[34.0,39.0]$} & 1,106 & 35 & {$[31.6,38.5]$} & 683 \\
\hline Yes & 63.5 & {$[61.0,66.0]$} & 1,925 & 65 & {$[61.5,68.4]$} & 1,269 \\
\hline Mother's education & & & & & & \\
\hline No education & 13.3 & {$[11.6,15.4]$} & 405 & 12.6 & {$[10.6,14.8]$} & 245 \\
\hline Primary & 54 & {$[51.1,56.8]$} & 1,635 & 53.9 & {$[50.9,56.9]$} & 1,053 \\
\hline Secondary + & 32.7 & {$[30.0,35.5]$} & 991 & 33.5 & {$[30.6,36.5]$} & 653 \\
\hline Father's education & & & & & & \\
\hline No education & 9.8 & {$[8.4,11.5]$} & 296 & 9.8 & {$[7.9,12.2]$} & 191 \\
\hline Primary & 50.6 & {$[48.0,53.1]$} & 1,524 & 44.1 & {$[41.2,47.1]$} & 856 \\
\hline Secondary + & 39.6 & {$[37.1,42.2]$} & 1,194 & 46.1 & {$[43.0,49.2]$} & 894 \\
\hline
\end{tabular}


Table 2: Percentage of children under age 2 who were stunted by child, maternal, household, and gender variables in Kenya and Cambodia, 2014 DHS

\begin{tabular}{|c|c|c|c|c|c|c|}
\hline \multirow{3}{*}{ Variable } & \multicolumn{3}{|c|}{ KENYA } & \multicolumn{3}{|c|}{ CAMBODIA } \\
\hline & \multicolumn{3}{|c|}{ Stunted } & \multicolumn{3}{|c|}{ Stunted } \\
\hline & $\%$ & CI & p-value & $\%$ & CI & p-value \\
\hline \multicolumn{7}{|l|}{ Age of child } \\
\hline Under 6 months & 9.9 & {$[7.7,12.7]$} & $<0.001$ & 15.2 & {$[11.4,20.0]$} & $<0.001$ \\
\hline 6-8 months & 11.6 & {$[7.7,17.1]$} & & 15.3 & {$[9.0,24.7]$} & \\
\hline 9-11 months & 16.2 & {$[12.1,21.2]$} & & 18 & {$[12.5,25.2]$} & \\
\hline 12-17 months & 28.8 & {$[24.6,33.2]$} & & 29.4 & {$[24.1,35.2]$} & \\
\hline 18-24 months & 32.6 & {$[28.5,36.9]$} & & 33.9 & {$[29.0,39.2]$} & \\
\hline Total & 22.1 & {$[20.0,24.2]$} & & 24.5 & {$[22.1,27.0]$} & \\
\hline \multicolumn{7}{|l|}{ Child's birth size } \\
\hline Small & 34.3 & {$[28.5,40.5]$} & $<0.001$ & 45 & {$[36.5,53.8]$} & $<0.001$ \\
\hline Average & 20.8 & {$[18.4,23.5]$} & & 24.6 & {$[21.4,28.1]$} & \\
\hline Large & 17.2 & {$[13.9,21.0]$} & & 17.7 & {$[14.3,21.6]$} & \\
\hline Total & 22.1 & {$[20.0,24.2]$} & & 24.4 & {$[22.1,27.0]$} & \\
\hline \multicolumn{7}{|l|}{ Birth interval } \\
\hline$<24$ & 24.2 & {$[20.8,27.9]$} & 0.006 & 28.5 & {$[20.9,37.6]$} & 0.149 \\
\hline $24-47$ & 23.9 & {$[20.9,27.1]$} & & 27.8 & {$[23.1,33.1]$} & \\
\hline $47+$ & 16.9 & {$[13.6,20.8]$} & & 22.8 & $\begin{array}{l}{[19.7,26.1]} \\
\end{array}$ & \\
\hline Total & 22.1 & {$[20.0,24.2]$} & & 24.5 & {$[22.1,27.0]$} & \\
\hline \multicolumn{7}{|c|}{$\begin{array}{l}\text { v Received all required vaccinations (DPT, Polio, } \\
\text { BCG, and Measles) }\end{array}$} \\
\hline Yes & 19.7 & {$[17.3,22.3]$} & 0.002 & 22 & {$[18.8,25.5]$} & 0.024 \\
\hline No & 25.4 & {$[22.4,28.7]$} & & 27.6 & {$[24.2,31.2]$} & \\
\hline Total & 22.1 & {$[20.0,24.2]$} & & 24.5 & {$[22.1,27.0]$} & \\
\hline \multicolumn{7}{|l|}{ Sex of child } \\
\hline Male & 25 & {$[22.1,28.2]$} & $<0.001$ & 26.5 & {$[23.3,29.9]$} & 0.057 \\
\hline Female & 19.1 & {$[16.7,21.7]$} & & 22.2 & {$[19.1,25.7]$} & \\
\hline
\end{tabular}




\begin{tabular}{|c|c|c|c|c|c|c|}
\hline Total & 22.1 & {$[20.0,24.2]$} & & 24.5 & {$[22.1,27.0]$} & \\
\hline \multicolumn{7}{|l|}{ Nutritional status } \\
\hline Not underweight & 21.7 & {$[19.5,24.1]$} & 0.509 & 23.1 & {$[20.4,26.1]$} & $<0.001$ \\
\hline Underweight & 23.6 & {$[18.8,29.2]$} & & 37 & {$[29.6,45.0]$} & \\
\hline Total & 21.9 & {$[19.8,24.2]$} & & 25.1 & {$[22.5,27.9]$} & \\
\hline \multicolumn{7}{|c|}{ Mothers age at 1st birth } \\
\hline$<18$ & 27.3 & {$[23.7,31.4]$} & 0.001 & 22.2 & {$[15.0,31.4]$} & 0.407 \\
\hline $18-24$ & 20.4 & {$[18.0,23.1]$} & & 25.6 & {$[22.8,28.6]$} & \\
\hline $25+$ & 15.9 & {$[11.1,22.2]$} & & 21.9 & {$[17.2,27.3]$} & \\
\hline Total & 22.1 & {$[20.0,24.2]$} & & 24.5 & {$[22.1,27.0]$} & \\
\hline \multicolumn{7}{|l|}{ Wealth index } \\
\hline Poorest & 29.2 & {$[25.8,32.7]$} & $<0.001$ & 35.5 & {$[30.3,41.2]$} & $<0.001$ \\
\hline Poorer & 24.6 & {$[20.6,29.2]$} & & 26.7 & {$[21.8,32.3]$} & \\
\hline Middle & 17.8 & {$[14.3,22.0]$} & & 23.5 & {$[18.4,29.5]$} & \\
\hline Richer & 21.4 & {$[16.8,27.0]$} & & 18.7 & {$[14.0,24.6]$} & \\
\hline Richest & 15 & {$[10.2,21.5]$} & & 13.8 & {$[9.9,18.9]$} & \\
\hline Total & 22.1 & {$[20.0,24.2]$} & & 24.5 & {$[22.1,27.0]$} & \\
\hline \multicolumn{7}{|l|}{ residence } \\
\hline Urban & 18.2 & {$[14.7,22.3]$} & 0.014 & 18.8 & {$[14.8,23.7]$} & 0.02 \\
\hline Rural & 24.2 & {$[21.8,26.8]$} & & 25.4 & {$[22.7,28.2]$} & \\
\hline Total & 22.1 & {$[20.0,24.2]$} & & 24.5 & {$[22.1,27.0]$} & \\
\hline \multicolumn{7}{|c|}{$\begin{array}{l}\text { Mother decides on own healthcare (alone or } \\
\text { jointly) }\end{array}$} \\
\hline No & 22.7 & {$[19.1,26.7]$} & 0.7 & 20.9 & {$[14.6,28.9]$} & 0.324 \\
\hline Yes & 21.9 & {$[19.6,24.3]$} & & 24.8 & {$[22.4,27.5]$} & \\
\hline Total & 22.1 & {$[20.0,24.2]$} & & 24.5 & {$[22.1,27.0]$} & \\
\hline \multicolumn{7}{|c|}{$\begin{array}{l}\text { Mother decides on large household purchases (alone or } \\
\text { jointly) }\end{array}$} \\
\hline No & 21.2 & {$[18.0,24.8]$} & 0.565 & 18.9 & {$[12.8,27.1]$} & 0.144 \\
\hline Yes & 22.5 & {$[19.9,25.3]$} & & 25 & {$[22.5,27.6]$} & \\
\hline
\end{tabular}


World Nutrition 2019(10):63-85

\begin{tabular}{|c|c|c|c|c|c|c|}
\hline Total & 22.1 & {$[20.0,24.2]$} & & 24.5 & {$[22.1,27.0]$} & \\
\hline \multicolumn{7}{|c|}{ Mother owns house (alone or jointly) } \\
\hline No & 20.4 & {$[16.8,24.5]$} & 0.223 & 20.6 & {$[17.2,24.4]$} & 0.011 \\
\hline Yes & 23.2 & {$[21.0,25.7]$} & & 26.8 & {$[23.8,30.1]$} & \\
\hline Total & 22.1 & {$[20.1,24.3]$} & & 24.5 & {$[22.1,27.0]$} & \\
\hline \multicolumn{7}{|c|}{ Mother owns land (alone or jointly) } \\
\hline No & 21.7 & {$[18.4,25.3]$} & 0.2574 & 22.5 & {$[18.9,26.4]$} & 0.16 \\
\hline Yes & 22.4 & {$[20.0,25.0]$} & & 26.1 & {$[23.0,29.6]$} & \\
\hline Total & 22.1 & {$[20.0,24.2]$} & & 24.5 & {$[22.1,27.0]$} & \\
\hline \multicolumn{7}{|c|}{ Mother worked in the past 12 months } \\
\hline No & 23.5 & {$[20.1,27.3]$} & 0.29 & 23.1 & {$[19.5,27.1]$} & 0.365 \\
\hline Yes & 21.2 & {$[18.9,23.8]$} & & 25.2 & {$[22.4,28.2]$} & \\
\hline Total & 22.1 & {$[20.0,24.2]$} & & 24.5 & {$[22.1,27.0]$} & \\
\hline \multicolumn{7}{|c|}{ Mother's education } \\
\hline No education & 26 & {$[21.3,31.2]$} & 0.005 & 29.1 & {$[22.1,37.4]$} & 0.064 \\
\hline Primary & 24.1 & {$[21.5,27.0]$} & & 25.8 & {$[22.5,29.4]$} & \\
\hline Secondary + & 17.2 & {$[13.6,21.4]$} & & 20.6 & {$[17.1,24.5]$} & \\
\hline Total & 22.1 & {$[20.0,24.2]$} & & 24.5 & {$[22.1,27.0]$} & \\
\hline \multicolumn{7}{|c|}{ Father's education } \\
\hline No education & 26 & {$[20.6,32.2]$} & 0.001 & 34 & {$[25.2,44.0]$} & 0.048 \\
\hline Primary & 24.9 & {$[22.2,27.9]$} & & 24.1 & {$[20.4,28.3]$} & \\
\hline Secondary + & 17.5 & {$[14.3,21.2]$} & & 22.3 & {$[19.2,25.8]$} & \\
\hline Total & 22 & {$[20.0,24.2]$} & & 24.3 & {$[21.9,26.8]$} & \\
\hline
\end{tabular}


Table 3: Results of logistic regressions of child stunting on child, maternal, household, and gender variables in Kenya and Cambodia, 2014 DHS

\begin{tabular}{|c|c|c|c|c|c|c|c|c|c|c|c|c|}
\hline & \multicolumn{4}{|c|}{ MODEL 1} & \multicolumn{4}{|c|}{ MODEL 2} & \multicolumn{4}{|c|}{ MODEL 3} \\
\hline & \multicolumn{2}{|c|}{ KENYA } & \multicolumn{2}{|c|}{ CAMBODIA } & \multicolumn{2}{|c|}{ KENYA } & \multicolumn{2}{|c|}{ CAMBODIA } & \multicolumn{2}{|c|}{ KENYA } & \multicolumn{2}{|c|}{ CAMBODIA } \\
\hline Characteristics & OR & CI & OR & CI & OR & CI & OR & CI & OR & CI & OR & CI \\
\hline \multicolumn{13}{|l|}{ Age of child } \\
\hline Under 6 months & 1 & & & & & & & & & & & \\
\hline 6-8 months & 1.1 & $\begin{array}{c}0.6- \\
1.9\end{array}$ & 1.0 & $\begin{array}{c}0.5- \\
1.9\end{array}$ & 1.2 & $\begin{array}{c}0.7- \\
2.0\end{array}$ & 0.9 & $\begin{array}{c}0.5- \\
1.6\end{array}$ & 1.1 & $\begin{array}{c}0.6- \\
2.0\end{array}$ & 0.8 & $\begin{array}{c}0.5- \\
1.5\end{array}$ \\
\hline 9-11 months & $2.0^{* *}$ & $\begin{array}{c}1.3- \\
3.2\end{array}$ & 1.4 & $\begin{array}{c}0.8- \\
2.5\end{array}$ & $2.1^{* *}$ & $\begin{array}{c}1.3- \\
3.4\end{array}$ & 1.2 & $\begin{array}{c}0.6- \\
2.2\end{array}$ & $2.1 * *$ & $\begin{array}{c}1.3- \\
3.5\end{array}$ & 1.2 & $\begin{array}{c}0.6- \\
2.2\end{array}$ \\
\hline $12-17$ months & $4.6^{* * *}$ & $\begin{array}{c}3.0- \\
7.2\end{array}$ & $2.7^{* * *}$ & $\begin{array}{c}1.7- \\
4.4\end{array}$ & $4.5^{* * *}$ & $\begin{array}{c}2.7- \\
7.6\end{array}$ & $2.3^{* *}$ & $\begin{array}{c}1.3- \\
3.8\end{array}$ & $4.6^{* * *}$ & $\begin{array}{c}2.7- \\
7.7\end{array}$ & $2.2^{* *}$ & $\begin{array}{c}1.3- \\
3.8\end{array}$ \\
\hline 18-24 months & $5.6 * * *$ & $\begin{array}{c}3.6- \\
8.7\end{array}$ & $3.8^{* * *}$ & $\begin{array}{c}2.3- \\
6.2\end{array}$ & $5.2 * * *$ & $\begin{array}{c}3.2- \\
8.5\end{array}$ & $3.2^{* * *}$ & $\begin{array}{c}1.9- \\
5.3\end{array}$ & $5.3^{* * *}$ & $\begin{array}{c}3.2- \\
8.8\end{array}$ & $3.1 * * *$ & $\begin{array}{c}1.8- \\
5.3\end{array}$ \\
\hline \multicolumn{13}{|l|}{ Child birth size } \\
\hline Small & 1 & & & & & & & & & & & \\
\hline Average & $0.5 * * *$ & $\begin{array}{c}0.3- \\
0.6\end{array}$ & $0.4^{* * *}$ & $\begin{array}{c}0.3- \\
0.6\end{array}$ & $0.4^{* * *}$ & $\begin{array}{c}0.3- \\
0.6\end{array}$ & $0.4^{* * *}$ & $\begin{array}{c}0.2- \\
0.6\end{array}$ & $0.4^{* * *}$ & $\begin{array}{c}0.3- \\
0.6\end{array}$ & $0.4 * * *$ & $\begin{array}{c}0.2- \\
0.6\end{array}$ \\
\hline Large & $0.3^{* * *}$ & $\begin{array}{c}0.2- \\
0.5\end{array}$ & $0.2^{* * *}$ & $\begin{array}{c}0.2- \\
0.4\end{array}$ & $0.3^{* * *}$ & $\begin{array}{c}0.2- \\
0.5\end{array}$ & $0.3^{* * *}$ & $\begin{array}{c}0.2- \\
0.5\end{array}$ & $0.3^{* * *}$ & $\begin{array}{c}0.2- \\
0.5\end{array}$ & $0.3^{* * *}$ & $\begin{array}{c}0.2- \\
0.5\end{array}$ \\
\hline \multicolumn{13}{|l|}{ Birth interval } \\
\hline$<24$ & 1 & & & & & & & & & & & \\
\hline $24-47$ & 0.8 & $\begin{array}{c}0.6- \\
1.2\end{array}$ & 1.2 & $\begin{array}{c}0.7- \\
2.0\end{array}$ & 0.9 & $\begin{array}{c}0.6- \\
1.3\end{array}$ & 1.1 & $\begin{array}{c}0.6- \\
2.0\end{array}$ & 0.9 & $\begin{array}{c}0.6- \\
1.3\end{array}$ & 1.1 & $\begin{array}{c}0.6- \\
1.9\end{array}$ \\
\hline $47+$ & $0.6^{*}$ & $\begin{array}{c}0.4- \\
0.9\end{array}$ & 0.8 & $\begin{array}{c}0.5- \\
1.3\end{array}$ & 0.7 & $\begin{array}{c}0.5- \\
1.1\end{array}$ & 0.8 & $\begin{array}{c}0.5 \text { - } \\
1.4\end{array}$ & 0.8 & $\begin{array}{c}0.5- \\
1.2\end{array}$ & 0.8 & $\begin{array}{c}0.5- \\
1.4\end{array}$ \\
\hline \multicolumn{13}{|c|}{ Received all required vaccinations (DPT, Polio, BCG, and Measles) } \\
\hline No & 1 & & & & & & & & & & & \\
\hline Yes & 0.8 & $\begin{array}{c}0.6- \\
1.1\end{array}$ & $0.7^{*}$ & $\begin{array}{c}0.5- \\
1.0\end{array}$ & 0.8 & $\begin{array}{c}0.6- \\
1.2\end{array}$ & 0.8 & $\begin{array}{c}0.6- \\
1.2\end{array}$ & 0.8 & $\begin{array}{c}0.6- \\
1.2\end{array}$ & 0.8 & $\begin{array}{c}0.6- \\
1.2\end{array}$ \\
\hline \multicolumn{13}{|l|}{ Sex of child } \\
\hline Male & 1 & & & & & & & & & & & \\
\hline
\end{tabular}




\begin{tabular}{|c|c|c|c|c|c|c|c|c|c|c|c|c|}
\hline Female & $0.6^{* * *}$ & $\begin{array}{c}0.5- \\
0.8\end{array}$ & $0.8^{*}$ & $\begin{array}{c}0.6- \\
1.0\end{array}$ & $0.6^{* * *}$ & $\begin{array}{c}0.5- \\
0.8\end{array}$ & 0.8 & $\begin{array}{c}0.6- \\
1.0\end{array}$ & $0.6 * * *$ & $\begin{array}{c}0.5- \\
0.8\end{array}$ & 0.8 & $\begin{array}{c}0.6- \\
1.0\end{array}$ \\
\hline \multicolumn{13}{|c|}{ Mother's nutritional status } \\
\hline $\begin{array}{l}\text { Not } \\
\text { underweight }\end{array}$ & 1 & & & & & & & & & & & \\
\hline Underweight & & & & & 0.8 & $\begin{array}{c}0.6- \\
1.1\end{array}$ & $1.7 *$ & $\begin{array}{c}1.1- \\
2.7\end{array}$ & 0.8 & $\begin{array}{c}0.6- \\
1.1\end{array}$ & $1.8 *$ & $\begin{array}{c}1.1- \\
2.8\end{array}$ \\
\hline \multicolumn{13}{|c|}{ Mothers age at 1st birth } \\
\hline 25 years + & 1 & & & & & & & & & & & \\
\hline $18-24$ years & & & & & 1.2 & $\begin{array}{l}0.7- \\
2.0\end{array}$ & 1.1 & $\begin{array}{c}0.8- \\
1.6\end{array}$ & 1.2 & $\begin{array}{c}0.7- \\
2.0\end{array}$ & 1.0 & $\begin{array}{c}0.7- \\
1.5\end{array}$ \\
\hline$<18$ years & & & & & 1.6 & $\begin{array}{c}0.9- \\
2.7\end{array}$ & 0.8 & $\begin{array}{c}0.4- \\
1.5\end{array}$ & 1.5 & $\begin{array}{c}0.8- \\
2.6\end{array}$ & 0.8 & $\begin{array}{c}0.4- \\
1.5\end{array}$ \\
\hline \multicolumn{13}{|l|}{ Wealth index } \\
\hline Poorest & 1 & & & & & & & & & & & \\
\hline Poorer & & & & & 0.8 & $\begin{array}{c}0.6- \\
1.1\end{array}$ & 0.7 & $\begin{array}{c}0.5- \\
1.1\end{array}$ & 0.8 & $\begin{array}{c}0.6- \\
1.1\end{array}$ & 0.7 & $\begin{array}{c}0.5- \\
1.1\end{array}$ \\
\hline Middle & & & & & $0.6^{* *}$ & $\begin{array}{c}0.4- \\
0.8\end{array}$ & 0.6 & $\begin{array}{c}0.4- \\
1.0\end{array}$ & $0.6^{* *}$ & $\begin{array}{c}0.4- \\
0.9\end{array}$ & $0.6^{*}$ & $\begin{array}{c}0.4- \\
0.9\end{array}$ \\
\hline Richer & & & & & 0.7 & $\begin{array}{c}0.4- \\
1.0\end{array}$ & $0.5^{*}$ & $\begin{array}{c}0.3- \\
0.9\end{array}$ & 0.7 & $\begin{array}{c}0.4- \\
1.1\end{array}$ & $0.5^{* *}$ & $\begin{array}{c}0.3- \\
0.8\end{array}$ \\
\hline Richest & & & & & $0.4^{* *}$ & $\begin{array}{c}0.2- \\
0.7\end{array}$ & $0.4^{* *}$ & $\begin{array}{c}0.2- \\
0.8\end{array}$ & $0.4^{* *}$ & $\begin{array}{c}0.2- \\
0.8\end{array}$ & $0.3^{* *}$ & $\begin{array}{c}0.2- \\
0.7\end{array}$ \\
\hline \multicolumn{13}{|l|}{ residence } \\
\hline Urban & & & 1 & & & & & & & & & \\
\hline Rural & & & & & 1.3 & $\begin{array}{c}0.9- \\
1.8\end{array}$ & $0.6^{*}$ & $\begin{array}{c}0.4- \\
0.9\end{array}$ & 1.3 & $\begin{array}{c}1.0- \\
1.9\end{array}$ & $0.6^{*}$ & $\begin{array}{c}0.4- \\
1.0\end{array}$ \\
\hline \multicolumn{13}{|c|}{ Mother decides on own healthcare (alone or jointly) } \\
\hline No & 1 & & & & & & & & & & & \\
\hline Yes & & & & & & & & & 1.0 & $\begin{array}{c}0.7- \\
1.4\end{array}$ & 0.9 & $\begin{array}{c}0.5- \\
1.4\end{array}$ \\
\hline \multicolumn{13}{|c|}{ Mother decides on household large purchases (alone or jointly) } \\
\hline No & 1 & & & & & & & & & & & \\
\hline Yes & & & & & & & & & 1.3 & $\begin{array}{c}0.9- \\
1.8\end{array}$ & 1.4 & $\begin{array}{c}0.8- \\
2.6\end{array}$ \\
\hline
\end{tabular}




\section{Mother owns house (alone or jointly)}

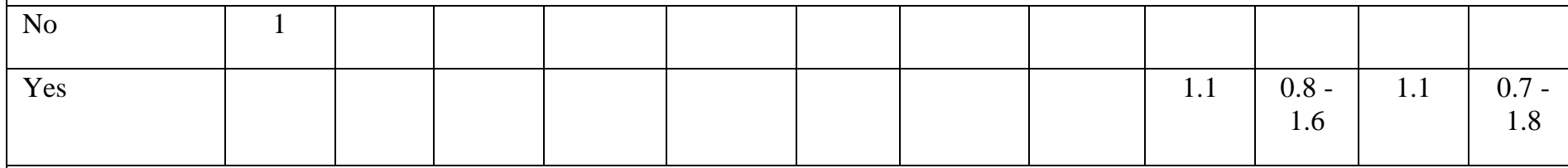

Mother owns land (alone or jointly)

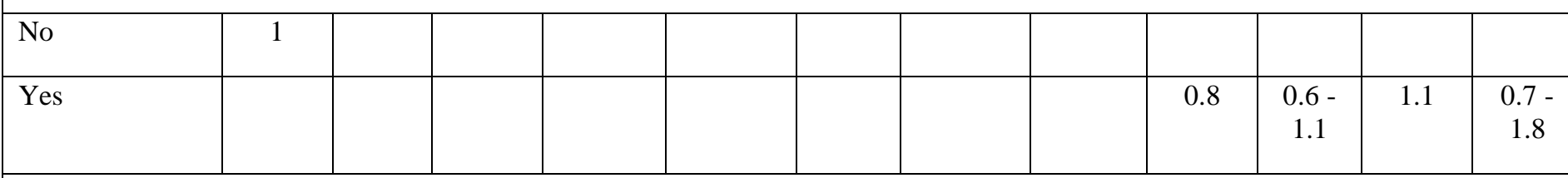

\section{Mother worked in the past 12 months}

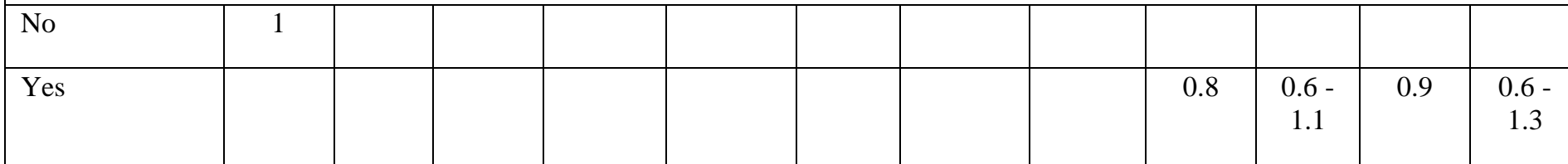

\section{Mother's education}

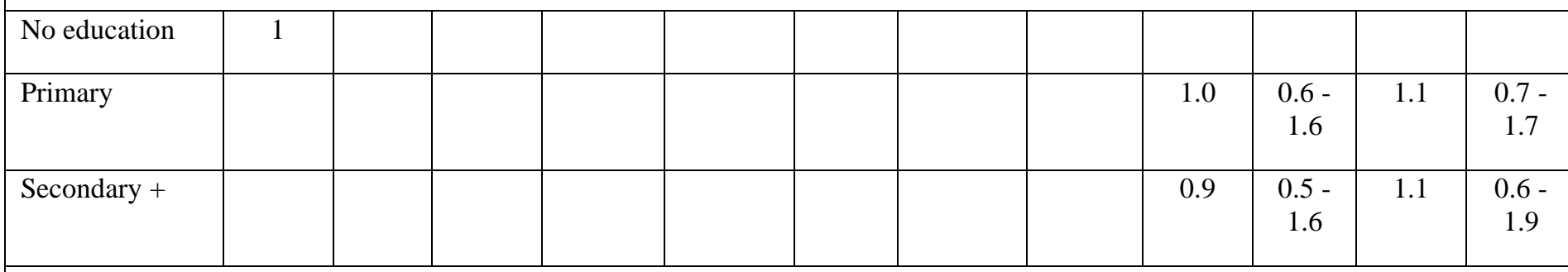

\section{Father's education}

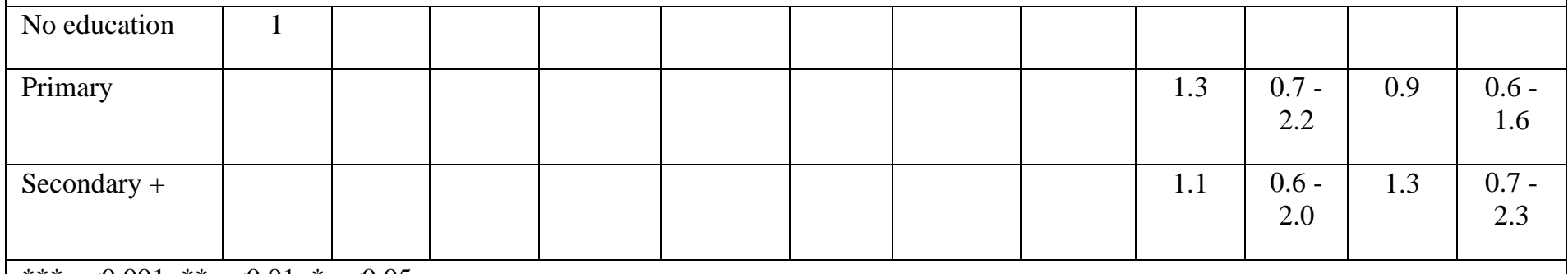

*** $\mathrm{p}<0.001,{ }^{* *} \mathrm{p}<0.01, * \mathrm{p}<0.05$

Notes: Model II and Model III control for region of residence 